\title{
Extrusion Diagonal Loaded of Centered Hole Sheet Metal Simulation and Analysis
}

\author{
Sayel M. Fayyad ${ }^{1}$, Ibrahim Edwan ${ }^{2}$, Waleed Momani ${ }^{3}$, Suleiman Abu-Ein ${ }^{4}$, \\ 1,3Department of Mechanical Engineering, Faculty of Engineering Technology, \\ 2Department of Mechanical Engineering, Faculty of Engineering Technology \\ P.O. Box 15008, Al-Balqa Applied University amman-jordan
}

\begin{abstract}
This paper presents a simulation and analysis to diagonal load affects on aluminum centered hole sheet metal stress and strain distributions and also deformations are distinguished. Many applications of metal forming included diagonal loading of such case. In many manufacturing processes this case is applied. Solidworks is used here to analyze such loads and their effects. It is found that the stress and the strain have maximum values at the fixed edge while the displacement has maximum values at the free end of the plate.
\end{abstract}

Keywords: - centered-hole metal sheet, deformation, diagonal loads, simulation strain, stress.

\section{INTRODUCTION}

This paper presents a simulation analysis for diagonal loading of sheet metal having a centered hole which can be found during extrusion or other manufacturing processes. Sheet metal extrusion differs from ordinary extrusion. Usually, the materials used in the process of sheet metal extrusion include mild steel and non-ferrous metal, and the thickness of the sheet metal plate suitable for extrusion is $2-20 \mathrm{~mm}$. The process is often an axisymmetric one. In that case, the diameters of the extrusion punch and the extrusion outlet are commonly greater than the thickness of the material. The extrusion ratio is generally no larger than 4.0. At the beginning, the sheet metal material is held tightly between the pressure ring and the die. Then, the punch penetrates the sheet metal material and extrudes it toward the outlet of the die. Not only extrusion but also penetration occurs during the sheet metal extrusion process. By contrast, only extrusion occurs in the ordinary extrusion process.

Although there has been a lack of analysis on sheet metal extrusion, the process has indeed existed and is developing quickly now. For example, the process can be used to manufacture a staged hole in the sheet metal material, or used in the combined fine-blanking and extrusion process. In order to develop the sheet metal extrusion process, it is necessary to clarify the theory behind the process. The model of sheet metal analyzed here is shown in figure (1) below.

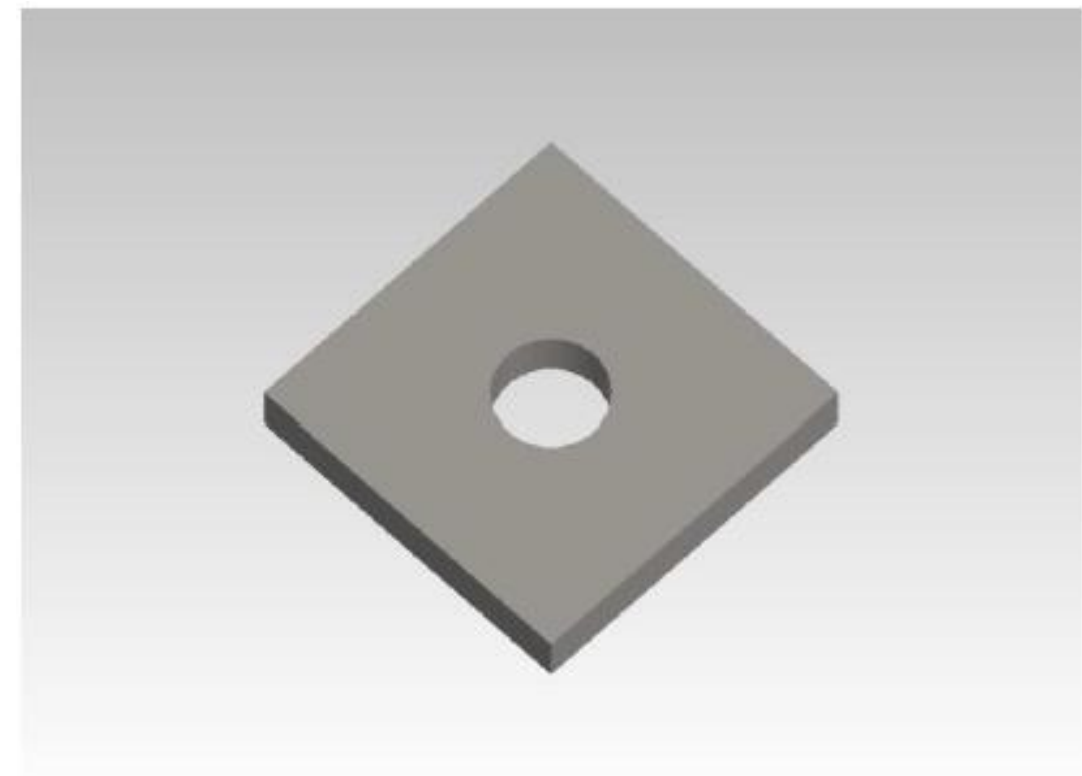

A 


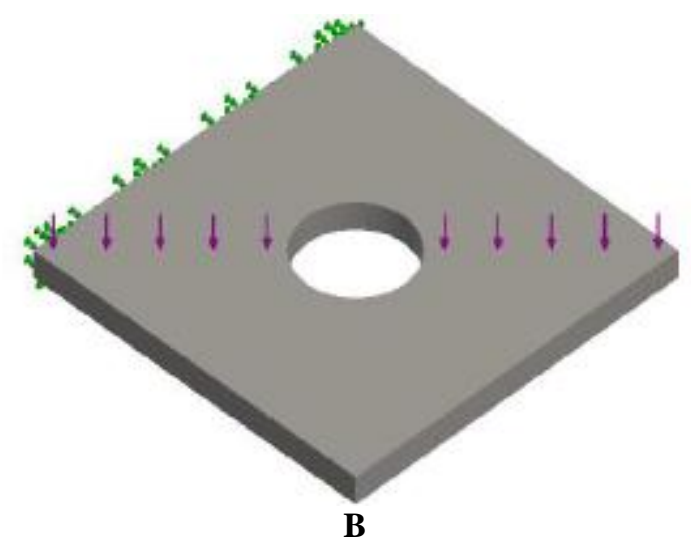

Fig. 1 a, $b$ the studied sheet metal

Little of researches treat this issue, P.F. Zheng et al. (2005), presented the characteristics of the process and gives a detailed analysis of it with the finite element method. According to the results, the mesh distortion, the field of material flow, and the distributions of the stress and strain can be predicted. Analysing the results from simulation, it is proposed that the extruded material can be divided into five areas according to their different features of deformation. In addition, the material in the areas of deformation can further be divided into three parts according to their different features of compression and elongation. The location of the fracture has been predicted from simulations. Some experiments have been carried out to verify the simulated results.

J. R. RICE, 1968, analyzed the stress and strain beside a notch of a sheet metal and it is found that it has the same value for all paths surrounding the tip of a notch in the two-dimensional strain field of an elastic or deformation-type elastic-plastic material

\section{RESULTS AND DISCUSSION}

Fig. 2 shows the meshed sheet metal to be analyzed using solidworks.

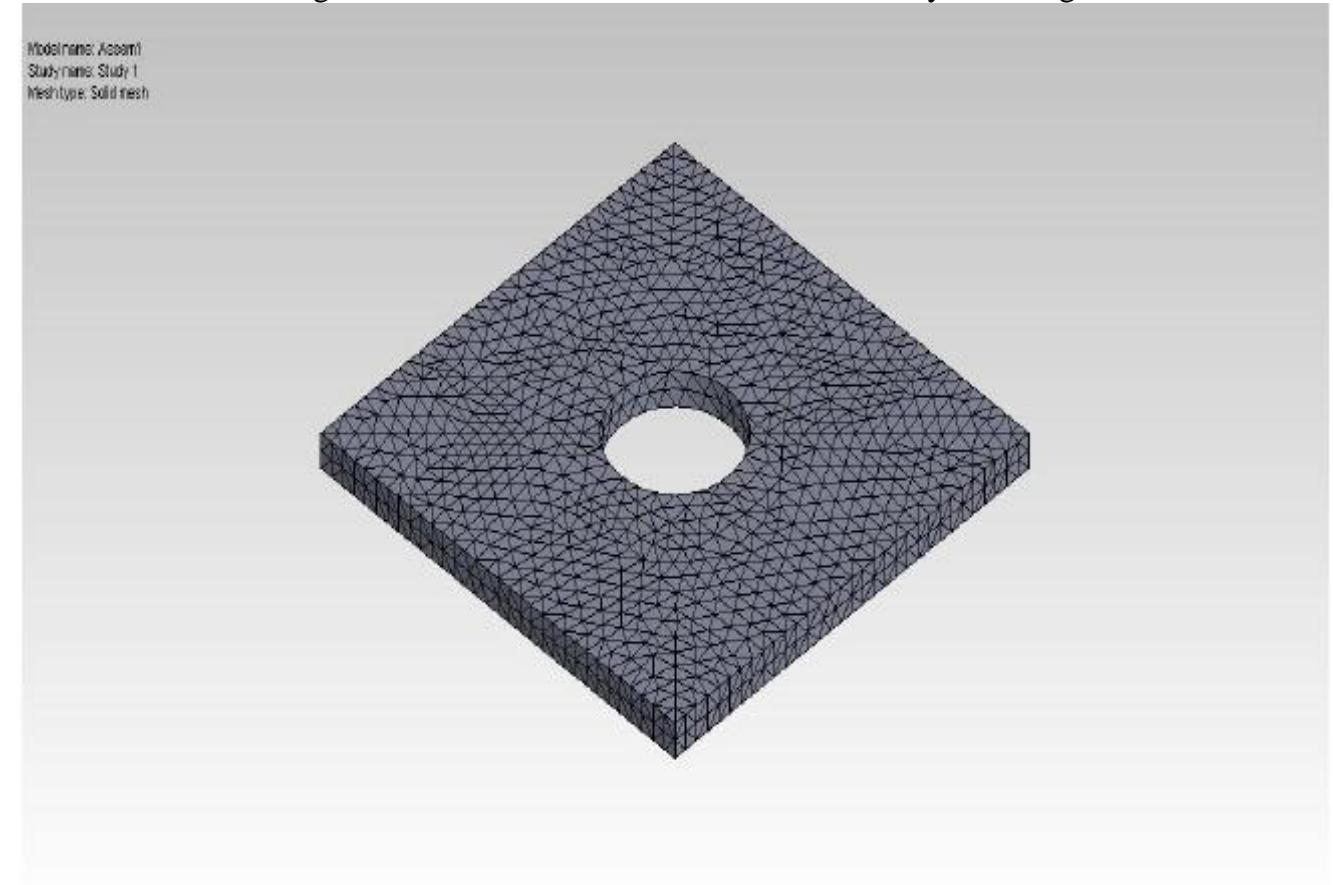

Fig.2 meshed sheet metal 
Fig. 3 shows the stress distribution of the sheet metal.

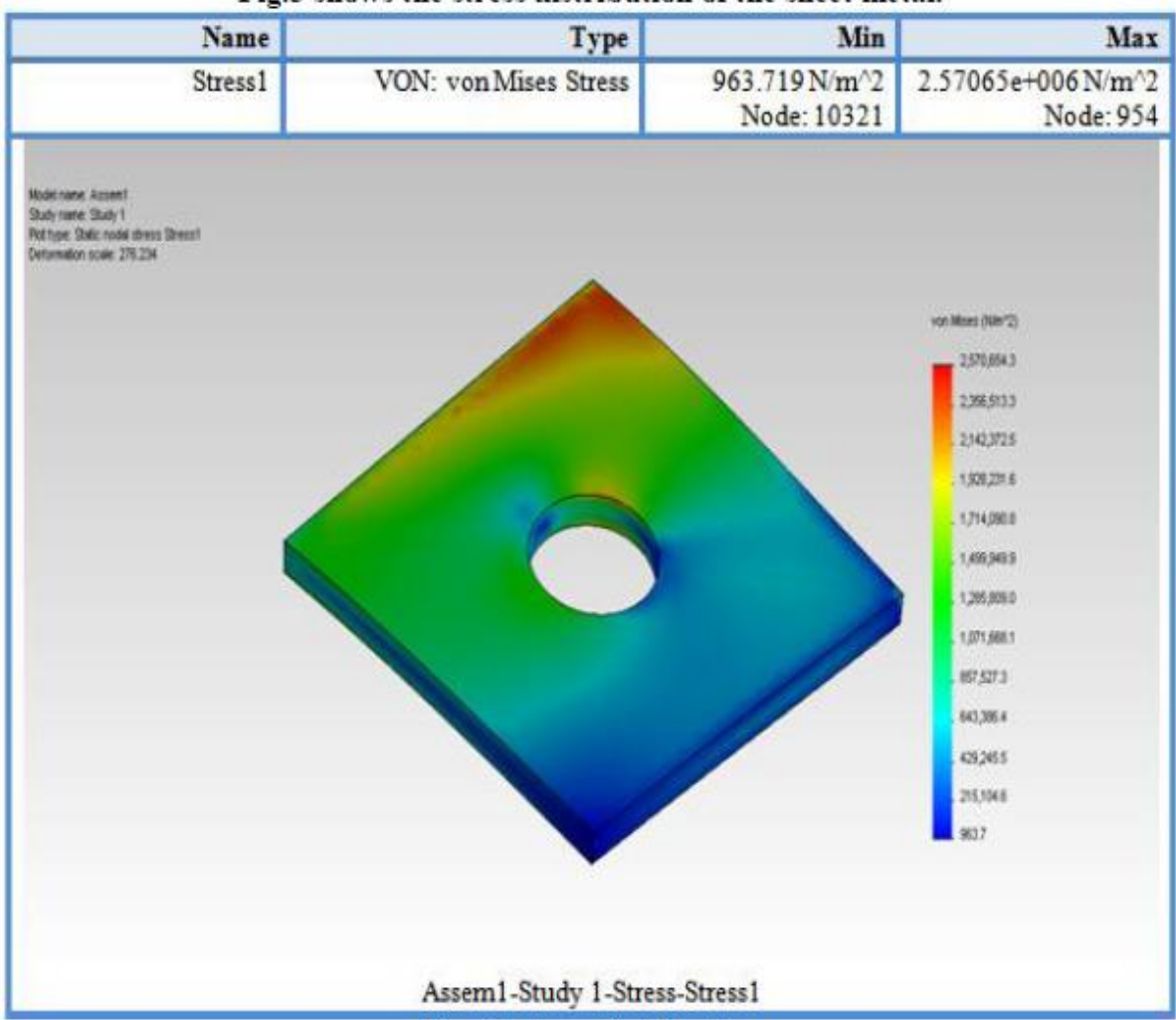

Fig. 3 stress distribution

Fig.4 shows the displacement and the strain distributions of the sheet metal.

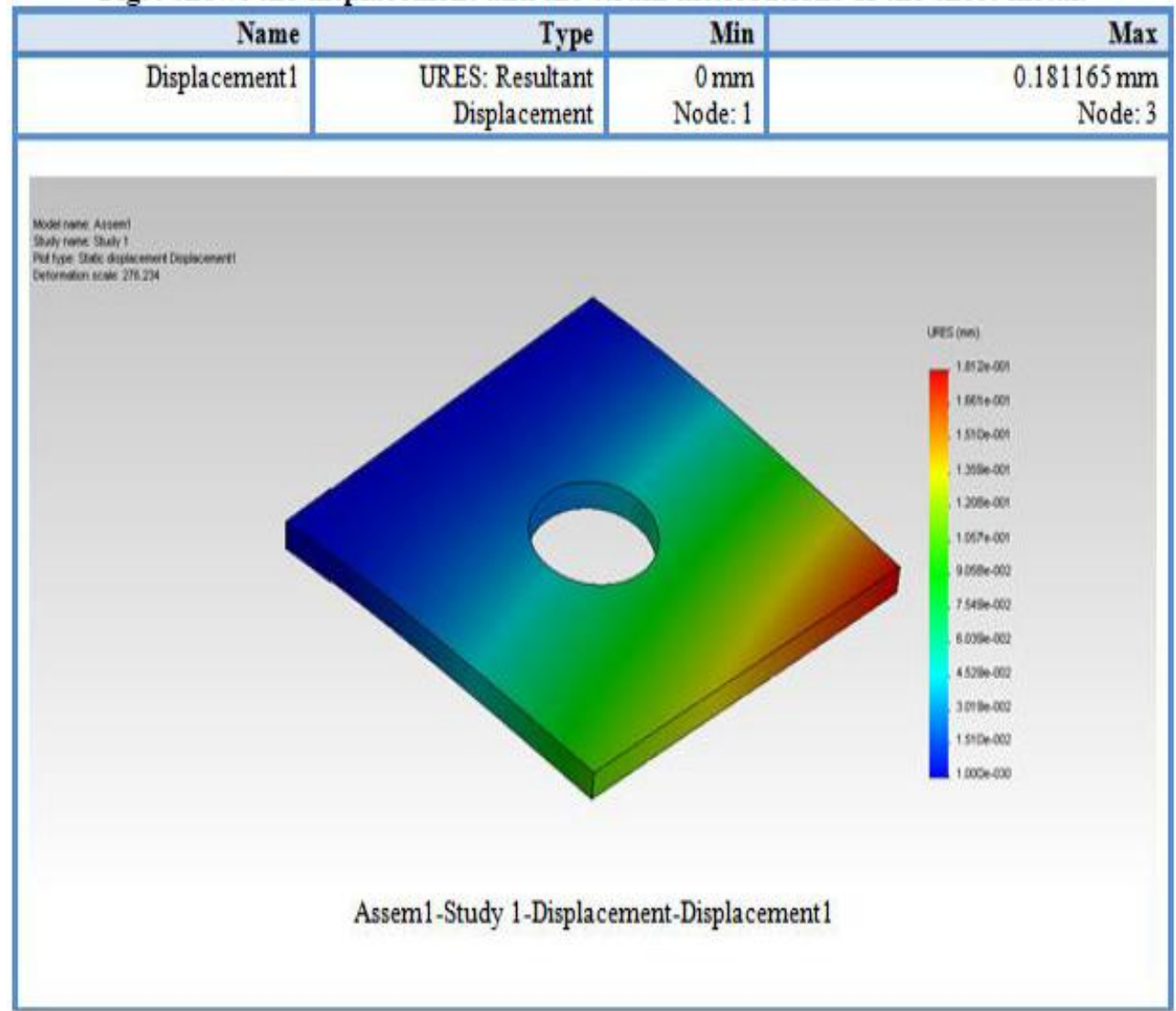




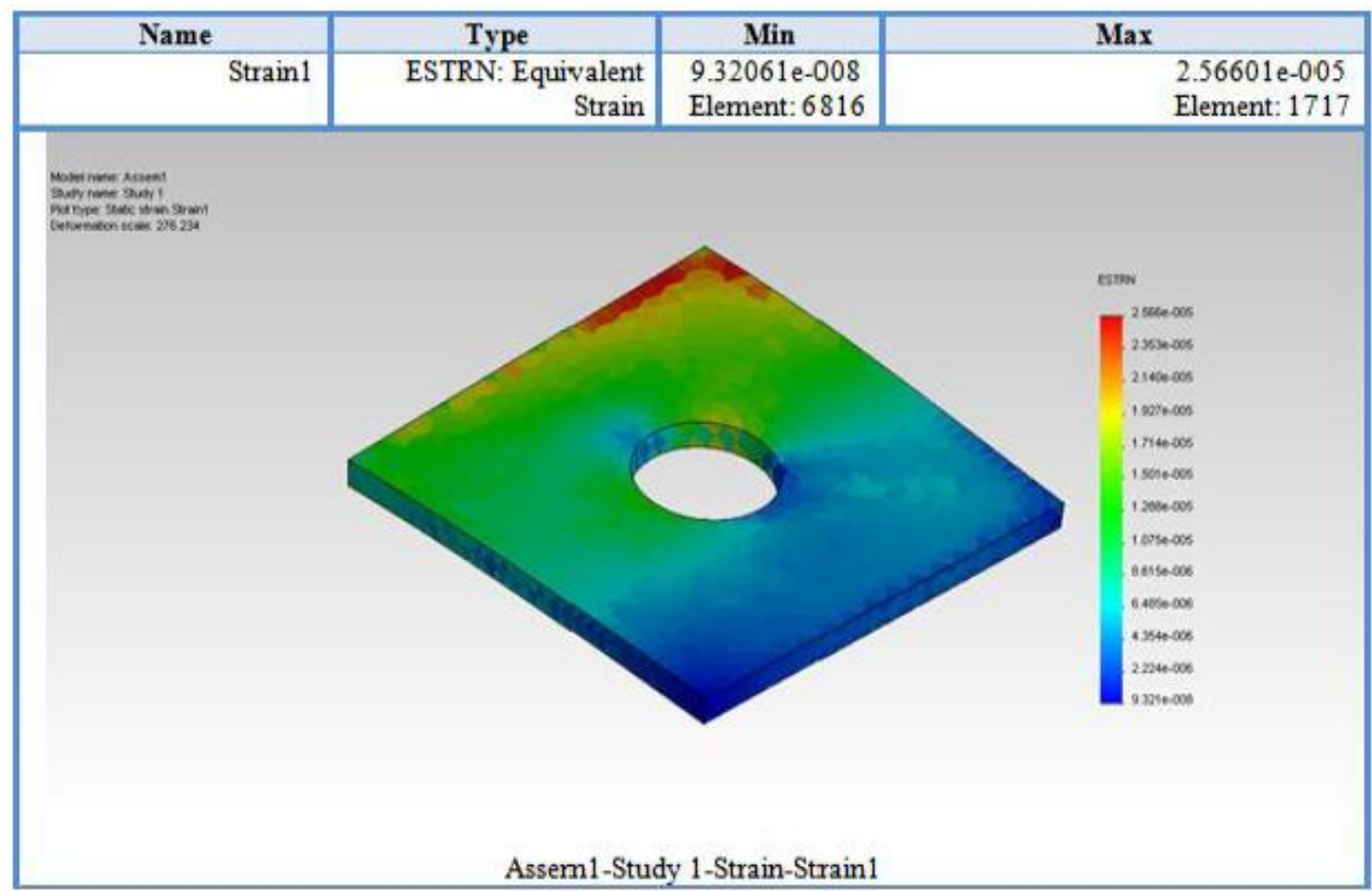

Fig.4 displacement and strain distributions

III. CONCLUSIONS

The stress, strain, and displacement distributions are studied here, it is found that the stress and the strain have maximum values at the fixed edge while the displacement has maximum values at the free end of the plate

\section{REFERENCES}

[1]. P.F. Zheng, L.C. Chan, T.C. Lee, 2005, Numerical analysis of the sheet metal extrusion process, Finite Elements in Analysis and Design 42 (2005) 189-207

[2]. J. R. RICE, 1968, A Path Independent Integral and the Approximate Analysis of Strain Concentration by Notches and Cracks, Journal of Applied Mechanics, vol. 35, pp. 379-386, 1968.

[3]. Jawad Ahmed Jadoon1 and Irfan A. Manarvi (2011), Wrinkling in Aluminum Sheet under Bi-Axial Loading using Finite Element Analysis, International Journal Of Multidisciplinary Sciences And Engineering, Vol. 2, No. 5, August 2011.

[4]. Phung Ngoc Dung, André Plumier, Behaviour of Expanded Metal Sheets under Shear Loading, Department of Construction, Hanoi Architectural University, Viet Nam KM N ${ }^{\circ} 10$, Nguyen Trai Street, Ha Noi, Viet Nam, Email : Dung.PhungNgoc@ student.ulg.ac.be, A.Plumier@ulg.ac.be

[5]. J.W. Hancock, A.C. Mackenzie, On the mechanisms of ductile failure in high-strength steels subjected to multi-axial stress-states, J. Mech. Phys. Solids 24 (1976) 147-169 